\title{
Procedimientos olvidados en ginecoobstetricia. Segunda parte
}

\author{
Emilio Alberto Restrepo Baena*
}

\begin{abstract}
RESUMEN: Continuámos con la descripción de varios procedimientos diagnósticos y terapéuticos que fueron usados a través de la historia de la ginecoobstetricia y que por lo agresivos o por la iatrogenia que generaban fueron descartados de la práctica actual.
\end{abstract}

PALABRAS CLAVES: Procedimientos, historia, iatrogenia.

SUMMARY: We continue describing several diagnosis and therapeutic procedures used in the past gineco obstetrical history and forgotten today because was very aggressive and iatrogenic.

KEY WORDS: Procedures, history, iatrogenic.

\section{Tratamientos para el prolapso genital}

La historia es testigo de la búsqueda frenética de tratamientos definitivos para este problema de tan común ocurrencia en el pasado por su asociación con la gran multiparidad y una obstetricia no muy profiláctica. Además de los intentos quirúrgicos de todo tipo (1), hubo unos procedimientos bastante llamativos y que revisamos a continuación:

Hipócrates proponía la "sucusión" como tratamiento bastante efectivo. La mujer con prolapso se ata a un armazón semejante a una escalera, piernas arriba de modo que la cabeza queda en la porción inferior del armazón. Los ayudantes la sacuden, ejerciendo tracción de la cuerda que sostiene los pies, hacia arriba, hacia abajo, más o menos rápidamente por sesiones de 3 a 5 minutos. El presupuesto teórico es que la gravedad volvería los órganos a su posición normal (2).

Polibio propone empacar la vagina con una esponja por varios días, también intentó colocar la mitad de una granada en el canal vaginal (?) (2).

Solano decía que perfumando con olores agradables la cabeza y el cuello de la paciente, se obliga al órgano prolapsado a ascender (2). Propone la opción de usar tapones de lino empapados con sustancias astringentes (?) (2).

Ambrose Pare utilizó ventosas y aparatos de plata, oro y latón que se introducían en la vagina y se fijaban con un cinturón (2).

R. de Castro proponía "atacarlo" con un pedazo de hierro al rojo vivo, como si fuera a ser quemado, obligando al útero prolapsado a "introducirse por temor" (2).

Se han utilizado también todo tipo de pesarios, de todas las formas, tamaños y materiales (1-2).

* Residente de Ginecoobstetricia Universidad de Antioquia

\section{Operación cesárea}

La operación cesárea ha conocido múltiples variaciones y técnicas en la búsqueda del perfeccionamiento y la disminución de sus riesgos y de la iatrogenia que se desprende de su realización.

A principios de este siglo aún estaba en voga la cesárea vaginal (que referenciamos en un artículo previo) (3-4) y la cesárea con exteriorización temporal del útero para casos de infección severa, cirugía descrita por Portes. Luego de la extracción del niño y la placenta y de la histerorafía, el útero se deja exteriorizado de 50 a 90 días, al cabo de los cuales, ya involucionado, se procede a limpiarlo y desinfectarlo, se libera el anillo cicatricial que circunda la pared abdominal y se reintegra a su posición cerrado por planos (4-5).

La pequeña cesárea abdominal o microcesárea, busca evacuar el útero grávido entre el cuarto y el octavo mes. Permite además, la esterilización en casos que contraindiquen el embarazo, como cardiopatías descompensadas, nefritis crónica, tuberculosis, gestosis, enfermedad de Addison, lesiones nerviosas, etc. La técnica está descrita con anestesia local (4, pág. 804).

\section{Uso de fórceps}

Los fórceps altos, en el estrecho superior, y por encima del mismo, se admitían, siempre y cuando "la pelvis sea normal, la proporción pélvico cefálica exista y el conducto del parto no ofrezca un obstáculo insalvable". Para ésto, el profesor J. C. Llames Massini aconsejaba: "cuando hay cierto grado de desproporción pélvico cefálico, sólo puede admitirse una cuchara del fórceps utilizada como palanca (fórceps maniobra) para conseguir el descenso del parietal anterior" (4, pág. 176).

Recomienda también fórceps en podálica; "cuando se intente una gran extracción pélvica en una presentación franca de nalgas y se desee que se encaje profundamente, 
estando en una variedad posterior, se debe usar un fórceps (por ejemplo el de Tarnier), aplicados a los muslos y caderas fetales" (4, pág 254$)$.

\section{Manejo del parto en podálica}

Además del anterior sistema, se recomienda como opción alternativa el uso de lazos y cintillas pasadas por los pliegues inguinales de una presentación podálica en variedad anterior y ejercer tracciones sostenidas (4, pág. 255).

Con el argumento que el volumen del polo pelviano es mayor que el cefálico y más irregülar, lo que ocasiona más desgarros, los autores recomiendan usarel balón de Champetier de Ribes (anteriormente referenciado para manejo de placenta previa sangrante (3), sobre todoen primigestantes en podálica, antes de pasar de 5 de dilatación. Esto se llama dilatación artificial prefetal, y si no hay balón, se puede realizar con la mano y el puño. Además de dilatar las partes blandas, se invoca una acción ocitócica (4, pág. 244).

Si por alguna razón hay retención de cabeza última, y la pelvis se considera estrecha, se puede recurrir a una operación ampliatoria de la pelvis (sinfisiotomía curativa con cabeza última). Si la causa es una dilatación incompleta del cervix se puede recurrir a incidir el cuello (4, pág. 248).

\section{Métodos para inducir o excitar la actividad uterina o provocar el parto}

El método de Mathieu consistía en ofrecer $60 \mathrm{cc}$ de aceite de ricino más un enema jabonoso, más 0.60 gr de sulfato de quinina, más $21 / 2 \mathrm{U}$ de pituitrina cada dos horas. Si hay gestosis o hipertensión, ésta se cambia por pitocín. Para sensibilizar la fibra uterina se usan inyecciones IM de foliculina. Si en lugar de quinina sola se usan $2 \mathrm{~cm}$ IV de quinina calcio más otros $4 \mathrm{~cm}$ IM, los resultados son mejores (4, pág. 294).

El método de Aburel preconiza inyectar 40 a $80 \mathrm{cc}$ de solución salina al $35 \%$ intrauterina (hasta $100 \mathrm{cc}$ en feto muerto).

El balón de Champetier de Ribes puede usarse intrauterino ya que además de dilatar mecánicamente el cuello, tiene acción ocitócica y desencadena el parto en pocas horas. Es el gran prestigio y aceptación y si se le agrega un peso constante es más eficaz (4, pág. 296).

Como dilatadores se usaron las Bujías de Hegar, numeradas de la 1 a la 30, lo mismo que la laminaria. Esta aumentaría hasta 5 veces su diámetro y actuaba en 16 a 24 horas.

También se usaron los dilatadores instrumentales de Bozzy (con 4 ramas) y los de Walcher (con 8 ramas). Se aplican en fases iniciales de dilatación y su labor la realizan desgarrando el cuello (4, pág. 301).

La técnica unimanual de Rizzoli, consiste en introducir el dedo índice al cuello y haciendo movimientos giratorios se van colocando más dedos hasta lograr tener toda la mano intrauterina en forma de cono.

La técnica bimanual de Bonnaire introduce los dos índices en aposición y trata de vencer la resistencia del cuello hasta permitir el ingreso de más dedos. La técnica bimanual de Harris es idéntica a la anterior pero las manos están entrecruzadas.
El método de Paul Delmas le agrega anestesia raquídea a la técnica de Rizzoli, obteniendo por relajación una fácil dilatación en minutos (de 3 a 10) (4, pág. 305).

Para pacientes con vaginas estrechas, estenóticas o en primiañosas se utilizó el debridamiento vagino perineal, que consistía en hacer una amplia sección quirúrgica que obtiene la dilatación artificial de la vagina y el perineo. Se coloca a la paciente en posición obstétrica y bajo anestesia general y cuidadosa preparación del campo operatorio, se secciona la vagina de adentro para afuera, de arriba hacia abajo y de atrás para adelante. Se repara por planos, los profundos con calgut, los superficiales con crin o ganchos metálicos, al igual que en la episiorrafía (4, pág. 786).

Las incisiones radiales de Duhrssenm superficiales o profundas, escasas o múltiples, laterales o mediales, ya fueron explicadas en una oportunidad anterior (3).

\section{Complicaciones del post-parto inmediato}

Para extraer una placenta anormalmente inserta se usa el método de Mojon-Gabastou que consiste en canalizar la vena umbilical, inyectar con buena presión de 500 a 1500 cc suero salino bien caliente. Esto busca obtener un hidrohematoma que despega la placenta (4, pág. 364).

Para una atonía uterina severa, y con el fin de realizar un taponamiento intrauterino a presión, se usaban los tubos de Cassel y de Gerofa Schwaab y el taponador de Beruti, de manejo sencillo y efectivo que se componían de un conector y de un embudo para introducir largos pedazos de gasa en el útero sin dejar espacio muerto (4, pág. 369).

Si hay necesidad de recobrar la volemia, La Plasmoterapia es el método de elección, ante los inconvenientes de la sangre total y del plasma líquido. Se usa plasma deshidratado (en polvo o desecado) con las ventajas de su duración ilimitada, no necesita refrigeración, transporte fácil, no hay incompatibilidad de grupo o Rh, contiene anticuerpos, complemento, elementos coagulantes y $3 / 5$ partes de las plaquetas. Para su uso se mezcla con agua destilada. Si se mantiene congelado, todos los elementos se conservan intactos (4, pág. 371).

\section{Manejo de las infecciones}

En las infecciones puerperales severas, con compromiso grave del estado general y cuando sólo se contaba con las sulfas como antibiótico, se recomienda, con relativo beneficio, la inyección intravenosa, gota a gota, de alcohol al $2 \%$ en 2400 cc de glucosa al 5\% en 24 horas. Dicen que la alcoholoterapia atenua la vitalidad de los gérmenes, ahorra energía al organismo, eleva el metabolismo básico, estimula el sistema retículo endoterial, es un antipirético débil por vasodilatación y por acción sobre los centros termorreguladores, tiene acción hipnótica, fácil absorción, moviliza lipoides. La glucosa es muy útil para el hígado (4, pág. 429).

Para la mastitis puerperal, además del reposo glandular y del drenaje de la leche, se recomienda el uso de purgantes, por su acción derivativa (?). Y en casos resistentes, radioterapia a dosis del $10 \%$ de las dosis que producen eritema, con muy buenos resultados (4, pág. 438). 


\section{BIBLIOGRAFIA}

1. Mattlingly R., Thompson J. Ginecología operatoria de Telinde. 6a. ed. Buenos Aires, Librería El Ateneo Editorial, 1987; 9.

2. Emge LA., Durfee RB. Prolapso vaginal, En: Clin. Obstet. Ginecol. México, Ed. Interamericana 1966; 997-1032.

3. Restrepo EA. Procedimientos olvidados en ginecoobstetricia. Rev. Col. Ginecol. 1993; 44: 17-19.
4. Morangues Bernat J. Clínica obstétrica. 2a. ed. Buenos Aires, Ed. El Ateneo 1942; 900.

5. Ruiz Velasco V. La operación cesárea. México, La Prensa Médica Mexicana, 1971; 1-30.

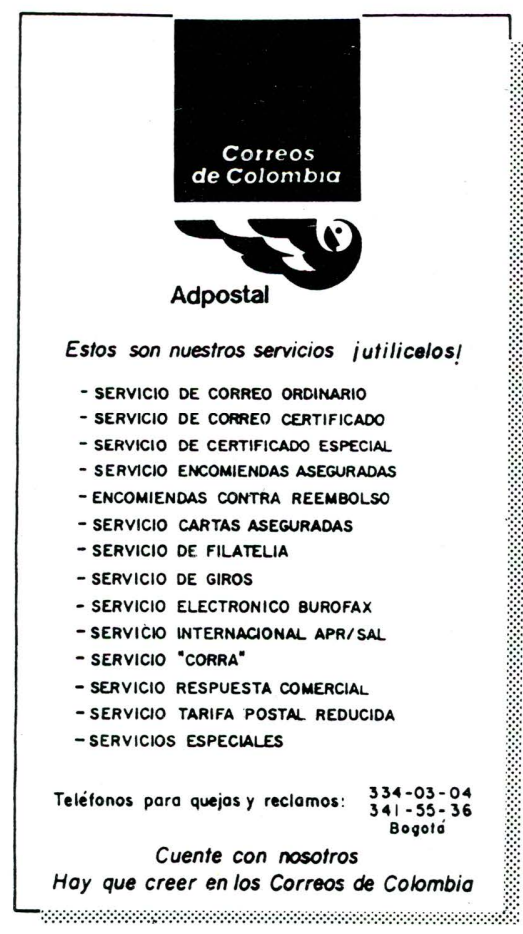

